\title{
LA SENTENCIA DEL TRIBUNAL EUROPEO DE DERECHOS HUMANOS, DE LA GRAN SALA, "D. H. Y OTROS CONTRA LA REPÚBLICA DE CHEQUIA", DE 13 DE NOVIEMBRE DE 2007
}

\author{
FERNANDO REY MARTÍNEZ
}

\begin{abstract}
RESUMO: O artigo examina a decisão do Tribunal Europeu de Direitos Humanos no caso "D.H. e outros contra a República Checa” de 13 de novembro de 2007. Este caso é um marco revolucionário na proteção das minorias raciais, especificamente dos ciganos, porque reconhece pela primeira vez elementos estatíticos como instrumentos probatórios eficazes na identificação de discriminação indireta ou de impacto discriminatório.

PALAVRAS-CHAVE: Discriminação Racial Indireta, Proteção das Minorias e Educação Infantil.
\end{abstract}

ABSTRACT: The article examines the decision of the European Court of Human Rights in the case "DH and others against the Czech Republic" of November 13, 2007. This case is a revolutionary milestone in the protection of racial minorities, especially the gypsies, because it recognizes, for the first time, statistics elements as effective probation instruments in identifying indirect discrimination or discriminatory impact.

KEYWORDS: Indirect Racial Discrimination, Protection of Minorities and Children's Education.

SUMÁRIO: $1^{\circ}$ ) Existe uma diferença dedutível de tratamento pelo diferente impacto da medida contestada? $2^{\circ}$ ) Inversão do ônus da prova. O governo se defende. $3^{\circ}$ ) Argumentação e conclusões do Tribunal, a) As provas psicológicas, b) O consentimento dos pais.

SUMMARY: 1)Is there a deductible difference of treatment by the different impact in the challenged measure? 2) Burden of proof reversal. The government defends itself. 3) Arguments and the Court's conclusions, a) The psychological evidences, b) The Parents' consent.

SUMARIO: $1^{\circ}$ ) ¿Existe una Diferencia de Trato Deducible por el Distinto Impacto de la Medida Impugnada? $2^{\circ}$ ) Inversión de la Carga de la Prueba. El Gobierno se Defiende. $3^{\circ}$ ) Argumentación y Conclusiones del Tribunal.

La Sentencia en examen marca un hito en la protección de las minorías raciales por parte del Tribunal de Estrasburgo. Esta institución se toma en serio por primera

\footnotetext{
* Doutorado em Direito pela Universidade de Valladoid, Espanha, com Especialização em Bioética. Professor do Departamento de Direito Constitucional, Direito Eclesiástico e Processual na mesma Universidade. Membro da Associação Espanhola de Direito Constitucional e da Associação Espanhola de Constitucionalistas.
} 
vez con carácter general la prohibición de discriminación racial (art. 14 Convenio Europeo de Derechos Humanos) revocando la Sentencia de Sala del mismo Tribunal, de fecha 7 de febrero de 2.006, que he tenido ocasión de comentar críticamente en diversos lugares ${ }^{1}$. En su voto discrepante, el Juez español J. Borrego compara esta Sentencia con un "coche de Fórmula 1", que se distancia con rapidez de la jurisprudencia anterior del Tribunal. Él juzga esta "arrancada” de modo negativo, pero personalmente creo todo lo contrario: el Tribunal Europeo de Derechos Humanos incorpora por primera vez en el ámbito de la discriminación racial (ya lo había hecho antes en relación con la discriminación sexual) las categorías del Derecho Antidiscriminatorio que usualmente utilizan tanto el Derecho de la Unión Europea (al que cita en apoyo expresamente en el texto) como en el Derecho norteamericano, del que procede, por ejemplo, el concepto de "discriminación indirecta” que es clave en el asunto resuelto. Esta Sentencia actualiza y pone al día la obsoleta categorización que en materia de igualdad y prohibición de discriminación venía manejando hasta ahora el Tribunal de Estrasburgo. Por primera vez aprecia una discriminación racial indirecta; por primera vez se aplica a este campo el valor probatorio de las estadísticas; por primera vez se incorpora el concepto de interpretación judicial estricta (que en el Derecho norteamericano se llama strict scrutiny test) en relación con la discriminación racial; por primera vez se ordena invertir la carga de la prueba en casos de discriminación racial indirecta o de impacto.

Por eso, esta decisión es importante no sólo por la solución que presta al conflicto concreto planteado, sino, sobre todo, por la doctrina general que establece respecto de la discriminación racial, aplicable en todos los casos sucesivos. Estamos, pues, en presencia de lo que (también en la cultura jurídica anglosajona) se conoce como un leading-case, una Sentencia que establece la doctrina a aplicar en el futuro.

Con carácter previo, hay que recordar que esta Sentencia es de la Gran Sala del Tribunal y revoca la anterior de una Sala del mismo Tribunal. Y es que el art. 43 del Convenio Europeo de Derechos Humanos permite, en “casos excepcionales” (por su importancia social, como éste, apreciada previamente por un colegio de cinco jueces) el "reexamen” de las Sentencias de Sala. Esta Sentencia es, por tanto, la última palabra de Estrasburgo sobre el conflicto en examen.

También con carácter propedéutico, procede llamar la atención sobre el hecho de que el Tribunal constata la situación social en desventaja de la comunidad gitana como criterio de interpretación del asunto. Literalmente, sostendrá (párrafo 181): “La posición vulnerable de los gitanos exige que se consideren de modo especial sus necesidades y estilos de vida diferentes en los marcos regulatorios generales y en las decisiones sobre casos particulares”. Es preciso, continúa la Sentencia, “salvaguardar los intereses de las minorías", pero también "preservar una diversidad cultural que tiene valor para toda la sociedad”.

Como se recordará, el problema se planteó por la diferencia de trato que los niños gitanos recibieron durante un cierto periodo de tiempo en la República checa

\footnotetext{
${ }^{1}$ Ver: “La discriminación racial en la jurisprudencia del Tribunal Europeo de Derechos Humanos”, Revista Española de Derecho Constitucional, núm. 79, enero-abril (2007), pp. 279-307.
} 
respecto de los niños no gitanos respecto de la escolarización, ya que un número muy elevado de niños gitanos eran ubicados en escuelas especiales para niños con discapacidades intelectuales. La Sentencia de Sala se había negado a conceder valor probatorio de la discriminación a los abrumadores datos estadísticos y por ello no llegó a considerar que se hubiera producido en el caso una discriminación indirecta o de impacto. La Sentencia de la Gran Sala imprime un giro copernicano, recordando que aunque la jurisprudencia del Tribunal “en el pasado” habían negado eficacia a las estadísticas como prueba para calificar una determinada práctica como discriminatoria, en casos más recientes sobre discriminación (por sexo) el Tribunal se apoyó en las estadísticas para identificar una diferencia de trato de grupos (mujeres y hombres) en situaciones similares. Concretamente, en la Sentencia Hoogendijk contra Holanda, de 6 de enero de 2.005, afirmó que: "Cuando un demandante es capaz de mostrar, sobre la base de estadísticas oficiales incontestables, la existencia de una indicación prima facie de que una regla específica (aún formulada de una manera neutral) afecta de hecho a un porcentaje claramente mayor de mujeres que de hombres, corresponde al Gobierno demandado demostrar que esto es el resultado de factores objetivos sin relación con cualquier tipo de discriminación por sexo. Si la carga de probar que una diferencia de impacto entre hombres y mujeres no es una práctica discriminatoria no correspondiera al Gobierno demandado, sería extremadamente difícil para los demandantes probar la discriminación indirecta”.

El Tribunal traslada esta metodología, punto por punto, desde el ámbito de la discriminación sexual al racial: Primero, la supuesta víctima de discriminación deberá aportar un principio de prueba, con la ayuda de estadísticas, de que existe una discriminación de impacto (o indirecta), esto es, una diferencia de trato entre dos grupos similarmente situados, a pesar de que el criterio de diferenciación no sea el racial, sino uno "neutro" (en este caso, serán las capacidades y necesidades educativas de los niños). No es necesario probar la existencia de una intención discriminadora por parte de la autoridad implicada. Segundo, esta alegación provocará una inversión de la carga de la prueba, de modo que no será quien alega la discriminación sino el Gobierno demandado el que intente demostrar que la diferenciación de trato (por el diverso impacto, insisto, no porque hay reglas distintas para cada grupo -en cuyo caso estaríamos en presencia de una discriminación de trato o directa) es objetiva y no tiene que ver de ninguna manera con una discriminación racial. Tercero, el órgano judicial decidirá a la vista de los argumentos planteados.

$\left.1^{\circ}\right)$ ¿EXISTE UNA DIFERENCIA DE TRATO DEDUCIBLE POR EL DISTINTO IMPACTO DE LA MEDIDA IMPUGNADA?

La Sentencia constata, en primer lugar, que a consecuencia "de una historia turbulenta", los gitanos se han convertido en un tipo específico de "minoría desventaja y vulnerable" que "requiere una protección especial”, sobre todo respecto del derecho a la educación (reconocido en el art. 2 del Protocolo núm. 1 del Convenio). Por eso este asunto merece "una atención especial”.

Pues bien, el Tribunal concede valor a los datos estadísticos que indican que el $56 \%$ de todos los niños en colegios especiales en Ostrava eran gitanos, aunque éstos sólo constituían el 2,26\% del total de alumnos en escuelas primarias en Ostrava. 
Además, sólo el 1,8\% de niños de niños no gitanos estaban en las escuelas especiales, mientras que la proporción de niños gitanos ascendía al 50,3\%. El Tribunal observa que el Gobierno checo no cuestionó estos datos y que no aportó otros distintos. Por otro lado, las estadísticas generales de todo el país confirmaban las de Ostrava: del total de alumnos en escuelas especiales, entre el 80 y el 90\% eran gitanos. Esto muestra, a juicio del Tribunal, una imagen más general que lleva a concluir que, incluso aunque las cifras no fueran exactas, el número de niños gitanos en escuelas especiales era desproporcionadamente alto. En consecuencia, estos datos estadísticos pueden considerarse fiables y significativos para probar una fuerte presunción de existencia de discriminación indirecta.

$2^{\circ}$ ) INVERSIÓN DE LA CARGA DE LA PRUEBA. EL GOBIERNO SE DEFIENDE.

Ante dicha presunción de discriminación indirecta, debe ser el Gobierno checo el que demuestre que la diferencia de impacto de su sistema escolar entre niños gitanos y no gitanos no está relacionada con el origen étnico. O, expresado más técnicamente, que existe una “justificación objetiva y razonable”, esto que, que persigue un fin legítimo y que existe una razonable relación de proporcionalidad entre los medios empleados y el fin perseguido. Cuando la diferencia de trato se basa en la raza, añade significativamente el Tribunal (incorporando el criterio de la interpretación judicial estricta), "la noción de justificación objetiva y razonable debe ser interpretada tan estrictamente como sea posible”.

Pues bien, el Gobierno checo justifica la diferencia de trato entre niños gitanos y no gitanos en la necesidad de adaptar el sistema educativo a la capacidad de los niños con necesidades educativas especiales. Y concreta la justificación de su política escolar en dos datos (que considera neutros y no discriminatorios por motivos raciales): $\left(1^{\circ}\right)$ Los niños eran ubicados en colegios especiales como resultado de su baja capacidad intelectual medida con la ayuda de pruebas psicológicas en centros de psicología escolar. $\left(2^{\circ}\right)$ La decisión final de derivar a los niños a los colegios especiales dependía del consentimiento de sus padres.

\section{$3^{\circ}$ ) ARGUMENTACIÓN Y CONCLUSIONES DEL TRIBUNAL.}

La Sentencia no va a considerar justificaciones objetivas y razonables a ninguna de las dos razones esgrimidas por el Gobierno (test psicológicos, consentimiento de los padres):

a) Las pruebas psicológicas.

El Tribunal acepta que el sistema de escuelas especiales (que más tarde, por cierto, fue abolido en Chequia, donde en la actualidad todos los niños están en escuelas ordinarias) estaba motivado por el deseo de encontrar una solución para los niños con necesidades educativas especiales. Sin embargo, comparte la inquietud, manifestada en el proceso por otras instituciones del Consejo de Europa sobre el pobre currículo que se seguía en tales escuelas y por la segregación que producía el sistema. Además, los test utilizados eran objeto de controversia científica y no tenían en cuanta las circunstancias específicas de los niños gitanos. El Tribunal concluye que, al menos, es deducible el peligro de que las pruebas psicológicas y sus resultados no fueran 
analizados a la luz de las circunstancias especiales de los niños gitanos. Y, por ello, no pueden servir como justificación de la diferencia de trato impugnada.

\section{b) El consentimiento de los padres.}

En las circunstancias del caso, el Tribunal no considera que los padres de los niños gitanos, que eran miembros de una comunidad en desventaja y con pobre formación, fueran capaces de valorar adecuadamente todos los aspectos de la situación y las consecuencias de su consentimiento. El Gobierno admite que tal consentimiento se prestaba mediante una firma en un impreso oficial que no aportaba información sobre alternativas o sobre las diferencias de currículo entre las escuelas ordinarias y las especiales. El voto discrepante del Juez español, J. Borrego, considera que esta tesis de la mayoría del Tribunal "es insultante" porque "juzga a los padres como incapaces de educar a sus hijos”. No puedo estar de acuerdo con esta objeción porque me parece manifiesta la falta de información que tenían los padres para tomar esa decisión y, sobre todo, como muy bien indica la propia Sentencia, porque los padres gitanos tenían ante sí el dilema de enviar a sus hijos a las escuelas ordinarias, que no estaban preparadas para incorporar las diferencias culturales y sociales de sus hijos, lo que con mucha probabilidad les condenaría inevitablemente al ostracismo, o de enviarles a las escuelas especiales donde se iban a encontrar con otros muchos niños gitanos.

El Tribunal concluye, pues, que ha habido una discriminación de impacto o indirecta, que provoca segregación y menos oportunidades para los niños gitanos. El sistema, tal como se aplicó en la práctica, tuvo un impacto desproporcionadamente perjudicial sobre la comunidad gitana y, en consecuencia, violó la prohibición de discriminación racial del Convenio (art. 14) en relación con el derecho a recibir educación (art. 2 P.A. n. 1).

Creo, en fin, que se trata de una magnífica Sentencia y no tanto por su aplicación al conflicto concreto (los hechos enjuiciados son ya, de alguna manera, irreparables aunque se produzca una condena dineraria y el sistema escolar ha cambiado posteriormente en Chequia), cuanto por la doctrina general sobre discriminación racial que, por fin, incorpora el Tribunal de Estrasburgo y que, sin duda, será aplicada en casos futuros. Discriminar a los gitanos en Europa será a partir de ahora un poco más difícil. Estamos de enhorabuena. 